\title{
THE FITNESS OF HYBRIDS BETWEEN TWO CHROMOSOMAL RACES OF THE GRASSHOPPER PODISMA PEDESTRIS
}

\author{
N. H. BARTON* \\ School of Biological Sciences, University of East Anglia, Norwich, NR4 7TJ
}

Received 15.i.80

\begin{abstract}
SUMMARY
Genetic incompatibilities between two races of the grasshopper Podisma pedestris, which differ by a Robertsonian fusion involving the sex chromosome, have been investigated. Crosses were made between four populations spanning the chromosomal cline; F1 hybrids between the races, though not between separated populations of the same race, showed markedly reduced hatching success. Observations of the fate of chromosomes transplanted across the cline supported this finding. Crosses between grasshoppers from a mixed population in the cline showed a lower average hatching success, but no correlation of this inviability with the chromosomal polymorphism. The karyotypes of pre-diapause embryos from both types of cross gave no evidence for non-disjunction of the sex chromosome trivalent in heterozygous females; an upper limit of 1.6 per cent can be set on the non-disjunction rate. These findings suggest that the karyotypic difference is only a weakly selected marker for more fundamental changes in genotype.
\end{abstract}

\section{INTRODUCTION}

OVER most of its range, the alpine grasshopper Podisma pedestris has the usual acridid XO sex chromosome system. In the Alpes Maritimes of south-eastern France, however, a Robertsonian fusion between the $\mathrm{X}$ chromosome and a large autosome has become established throughout a large area, giving rise to a neo-XY sex chromosome system (John and Hewitt, 1970; Hewitt and John, 1972; Hewitt, 1975). These two chromosomal races meet in a long narrow hybrid zone which runs east-west for about $100 \mathrm{Km}$ along a high mountain ridge. The eastern end of the zone, near Col de Tende, has been studied in some detail; it has been found that there is a chromosomal cline, about $800 \mathrm{~m}$ wide, which runs from the lower limit of the species' distribution at $1500 \mathrm{~m}$ altitude, through a wide variety of terrain, up to some barren mountains at $2800 \mathrm{~m}$. No allozymic differences have yet been detected between the races, but a distinct difference in shape is associated with the karyotypic difference in mixed populations (Barton, $1979 a$; Hewitt and Barton, 1979; Barton and Hewitt, 1980a; Halliday and Hewitt, personal communication).

The most plausible explanation for the maintenance of this chromosomal cline is that hybrids between the two races are in some way less fit than their parents (see Barton and Hewitt, 1980a). Indeed, the most obvious effect of a Robertsonian fusion is to lower the fertility of heterozygotes, through the production of unbalanced gametes by non-disjunction (White, 1973). To test this hypothesis, I have carried out some laboratory crosses. It is, of

\footnotetext{
* Present address: Department of Genetics, Downing Street, Cambridge CB2 3EH.
} 
course, dangerous to assume that fitness measured under laboratory conditions accurately reflects fitnesses in the field. However, many components of selection against hybrids may not depend too much on external effects. For example, the rate of chromosomal non-disjunction should not be very sensitive to the outside environment. The results from these crosses should be treated with caution, but the measurement of selection against hybrids is not as difficult as, say, the measurement of the selective effects of different environments.

Crosses have been made between grasshoppers collected from chromosomally pure populations spanning the cline, and also between grasshoppers from a mixed population within it. The first set of crosses shows the cumulative selective effect of all the differences between the chromosome forms, whilst the second set shows the effect of the chromosomal difference itself, and of any other differences which are closely linked to the Robertsonian fusion. Fitness involves many factors; meiosis, embryonic development, hatch rate, nymphal and adult viabilities, mating success, and fertility. All of these have been investigated to some extent, but effort was concentrated on the meiotic, embryonic, and hatching stages. In particular, the second generation from crosses between pure populations was killed and karyotyped early in embryonic development. This strategy was followed because many more eggs than adults can be produced and scored, and because viability in later stages, and mating success, are more sensitive to external conditions. This analysis of selection is thus incomplete, but covers the stages in the life cycle most sensitive to chromosomal changes.

In order to get some direct evidence of the action of natural selection in the field, and also to provide a measure of the rate of gene flow, grasshoppers were exchanged between two chromosomally pure populations. The fate of the transplanted chromosomes was followed over the next two years by the collection and karyotyping of large samples of males. Though the numbers transplanted were small, this transplant experiment gives some confirmation of the results obtained from the laboratory crosses.

\section{METHOdS (MODIFIED FROM KELLY-STEBBINGS AND HEWITT, 1972)}

\section{(i) Crosses between pure populations}

In the early July of 1977 , about 100 immature grasshoppers were collected from each of four populations in the study region near Col de Tende. Two of these sites, denoted by $\mathrm{O}$ and $\mathrm{O}^{\prime}$, are occupied by the XO race; they are about $3 \mathrm{Km}$ apart, separated by a river, and are about $3 \mathrm{Km}$ from the cline. The other two sites, denoted by $Y$ and $Y^{\prime}$, are about $6 \mathrm{Km}$ apart, and $4 \mathrm{Km}$ from the cline (fig. 1). Thus, simple isolation by distance can be distinguished from inter-racial divergence.

These nymphs were brought back to the laboratory within 48 hours. Very few died in transit, and they later did as well as grasshoppers hatched in the laboratory. The four samples were reared to adulthood in standard locust cages at $20-23^{\circ} \mathrm{C}$ by day, and $10-15^{\circ} \mathrm{C}$ by night, and were fed on nettles, plantain, and comfrey; in addition, radiant heat was supplied by light bulbs.

As the nymphs moulted to become adult, single pair crosses were set up in individual cages. There was some difference between the samples in 


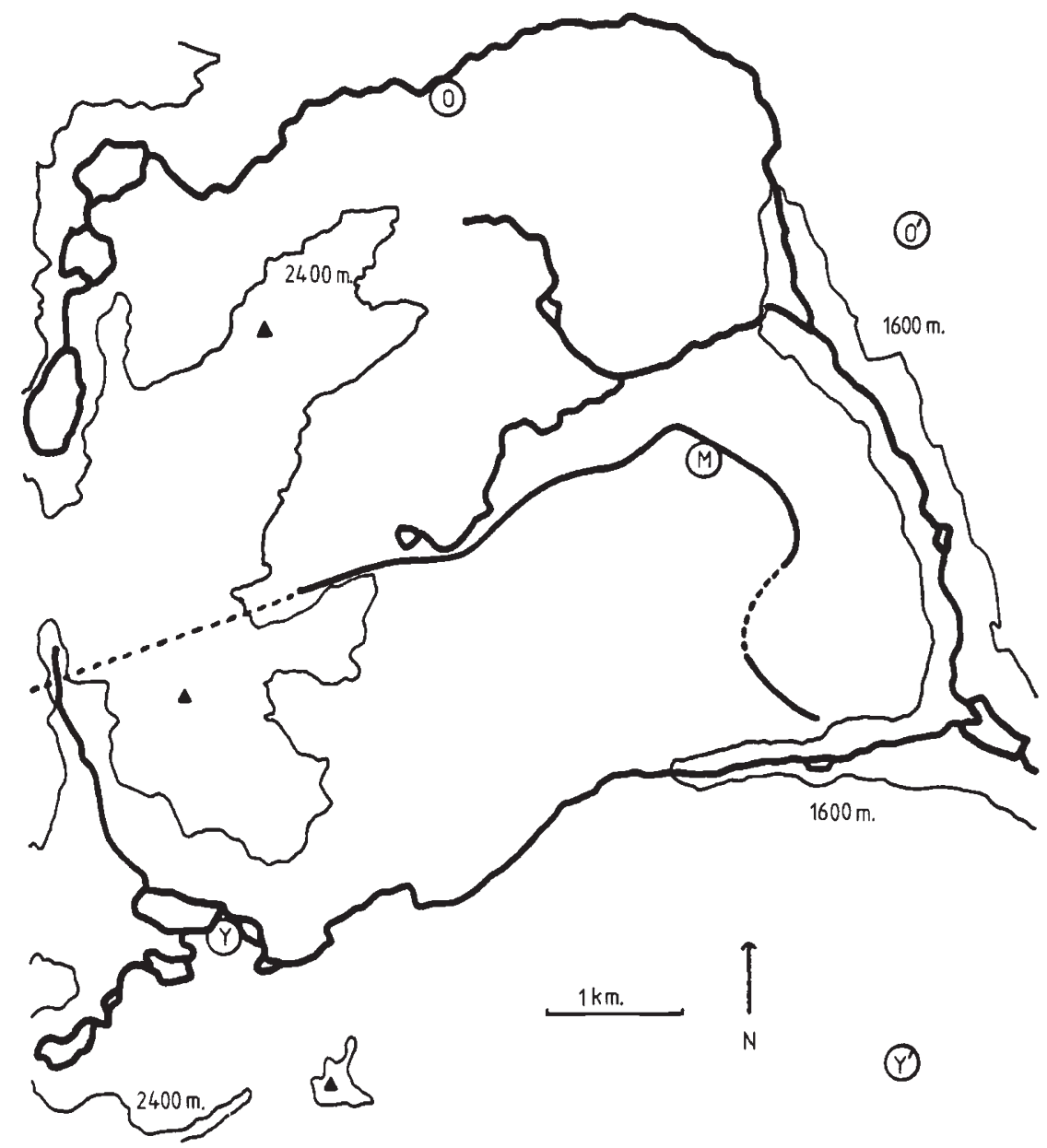

FIG. 1.-The positions of the four distant sites $\left(\mathrm{O}, \mathrm{O}^{\prime}, \mathrm{Y}, \mathrm{Y}^{\prime}\right)$, and the mixed site $(\mathrm{M})$. The chromosomal cline is marked by a thick line; in dotted sections, no mixed populations have yet been found. Major peaks and rivers, and two contours, are also shown.

emergence time, but males emerge a few days earlier, so that inter-racial crosses could always be set up using newly emerged females; male age probably affects fertility less than female age. The feeding and temperature regime was as for adults. Four blocks of 16 cages were set up, each containing all possible pairwise combinations of the 4 samples. The cages were laid out in a Latin Square design, to minimise the effect of temperature variations through the insectary.

After about ten days of adult life, females began to lay pods of 20 or so eggs, in moist peat-sand mix. Pods were laid at intervals of two to three days; after the first pod, the male was frozen, after his testes had been fixed, for later karyotypic, morphometric, and electrophoretic analysis. By this time, pairs had mated many times, and the female had a good store of sperm. After she had laid two or three pods, the female was frozen. Though more pods could have been obtained, the body was needed for electrophoresis, so 
that the Mendelian inheritance of electrophoretic variation could be confirmed.

The egg pods were stored in separate Petri dishes, filled with moist sand, at room temperature for 3 months. During this period, the embryo grew to fill the egg, and then went into a quiescent diapause (see Hewitt and East, 1978 for an account of grasshopper development). The eggs were then kept at $1^{\circ} \mathrm{C}$ for 5 months, simulating winter conditions and breaking the diapause. In the spring the eggs were put into a $26^{\circ} \mathrm{C}$ incubator to hatch. After 2-3 days, as they began to hatch, the pods were transferred in their Petri dishes to large locust cages; the various classes of cross were kept separate if they differed by race, but crosses differing only by population were pooled (table 1 ). The hatch rate, and the numbers of dead just after hatching could be

TABLE 1

Nymphs from 4 populations spanning the cline $\left(O, O^{\prime}, Y, Y^{\prime}\right)$ were collected in July, 1977, and set up as single pairs. The offspring of these crosses were reared in 8 bulk cages; this table details the contents of each cage. Throughout, the male type is given by the first character; for example, $O Y^{\prime}$ denotes a cross between a male from population $O$ and a female from population $Y^{\prime}$. Classes which differed chromosomally were never merged

\begin{tabular}{|c|c|c|}
\hline Cage name & Contents & \multirow{3}{*}{ Pure XO } \\
\hline OO & $\mathrm{OO}, \mathrm{O}^{\prime} \mathrm{O}^{\prime}, \mathrm{O}^{\prime} \mathrm{O}$ & \\
\hline $\mathrm{OO}^{\prime}$ & $\mathrm{OO}^{\prime}$ & \\
\hline $\begin{array}{l}\text { YY } \\
\text { YY' }\end{array}$ & $\begin{array}{l}Y Y, Y^{\prime} Y^{\prime} \\
Y Y^{\prime} Y^{\prime} Y\end{array}$ & \multirow[t]{2}{*}{ Pure XY } \\
\hline OY & $\mathrm{OY}, \mathrm{O}^{\prime} \mathrm{Y}^{\prime}$ & \\
\hline YO & $Y O, Y^{\prime} O^{\prime}$ & \multirow{3}{*}{ F1 hybrid } \\
\hline $\mathrm{Y}^{\prime} \mathrm{O}$ & $\mathrm{Y}^{\prime} \mathrm{O}, \mathrm{YO}^{\prime}$ & \\
\hline OY' & $\mathrm{OY}^{\prime}, \mathrm{O}^{\prime} \mathrm{Y}$ & \\
\hline
\end{tabular}

scored separately for each cross, but after that, only pooled data are available. As the number of possible crosses between 16 parental types is large, it would not have been feasible to keep all the progeny separate.

As the insects became adult, single pairs were set up as before. Males were frozen, and their testes fixed, after their mate had laid one or two pods, but females were allowed to go on laying until they died. This greatly increased the number of eggs obtained, but meant that only one parent was available for electrophoresis. The egg pods were fixed after 21-25 days of development at room temperature, to allow the investigation of their karotype (for details see Hewitt and East, 1978).

\section{(ii) Crosses between grasshoppers from within the cline}

In the early part of August 1978, roughly 200 nymphs were collected from an area less than 40 metres across (site 121 of Barton and Hewitt, $1980 a$, and $M$ in fig. 1). Gene frequencies should change little over this distance; the population was very dense, and there were no barriers to dispersal across this open meadow. The insects were brought back to Norwich, reared to adulthood in bulk cages, and set up in single pair crosses as before. The females were allowed to lay until they died, and so only males 
were available for karyotypic and electrophoretic analysis. Half the pods from each cross were fixed before diapause for karyotyping, as before, and half were hatched out after 3 months at room temperature, and 4.5 months at $1{ }^{\circ} \mathrm{C}$. The karyotypes of the parents could be deduced unambiguously from the karyotypes of the progeny; the karyotypes of the other pods from the same cross were thus known by inference.

\section{(iii) The transplant experiment}

In 1976, two sites of differing karyotype, in Valmasque and at Lac Long, were chosen for a transplant experiment (these sites are within 200 metres of sites $\mathrm{O}$ and $\mathrm{Y}$, respectively). As soon as the population became largely adult, young grasshoppers of both sexes were collected from each, marked with paint, and scattered over the same site on the same morning. A few hours later, a sample was collected from the area over which the marked insects had been scattered. The proportion of marked grasshoppers in this sample gave a measure of the fraction of the population which had been caught; collecting continued until about a third of the marked insects had been recaptured. Some of the insects were retained for karyotypic and electrophoretic analysis, and the remainder were released early the next morning, whilst still cold and immobile, at the centre of the opposite site. In the following years, large samples of males were taken from up to 30 metres around the release points, and karyotyped to detect the transplanted chromosome type. These were marked individually by removing a unique combination of leg joints, so that the position of each male was known.

\section{Results}

(i) Crosses between pure populations

The date of laying a pod, and the numbers of eggs per pod, did not differ significantly between the hybrid and non-hybrid crosses. This was to be expected, since these variables are characteristics of the female rather than of the cross. However, there was a large difference in hatching success between chromosomally hybrid and non-hybrid crosses (table 2(a)). No such incompatibility was found in crosses between grasshoppers from different sites within the same race; the differential mortality is associated with the chromosomal difference, and is not just due to divergence between distant populations. Pods were dissected, and the unhatched eggs were classified according to the stage of development of the dead embryo (table 2(b)). The hybrid crosses showed an excess of embryos which ceased development very early, and also of embryos which died as they were hatching.

In judging the strength of selection, the parameter of interest is the mean hatch rate. This will determine the numbers which survive to breed from a given number of eggs. Since most of the variation was due to differences in female quality, rather than to sampling error in determining the hatch rate of each cross, it is reasonable to weight crosses equally, rather than by the number of eggs laid. The observed mean hatch rates were 0.55 in nonhybrid crosses, and 0.28 in hybrid crosses, implying a 50 per cent selective force acting against hybrids. Although the numbers of crosses involved were 
TABLE 2

Sections $(a)$ and $(c)$ give the numbers of crosses in each class, and the corresponding hatch rates. The latter were determined by dissecting the pods after hatching; survival to second instar was much lower. The proportion of eggs which were found in various states is given in sections $(b)$ and $(d)$. H-successfully hatched. $R$-died and rotted just after hatching. $P D$-developed past diapause but failed to hatch. BD-stopped developing at or before diapause. UD-little or no embryonic material found

(a) Hatch rates from crosses between distant populations

Non-hybrid

Hybrid

$\begin{array}{ccclcc}\text { Cross } & \text { No. of crosses } & \text { Hatch rate } & \text { Cross } & \text { No. of crosses } & \text { Hatch rate } \\ \text { YY, } \mathrm{Y}^{\prime} \mathrm{Y}^{\prime} & 8 & 0.62 & \mathrm{OY}, \mathrm{O}^{\prime} \mathrm{Y} & 5 & 0 \cdot 30 \\ \mathrm{OO}, \mathrm{O}^{\prime} \mathrm{O}^{\prime} & 9 & 0.40 & \mathrm{O}^{\prime} \mathrm{Y}^{\prime}, \mathrm{OY}^{\prime} & 7 & 0 \cdot 31 \\ \mathrm{YY}^{\prime}, \mathrm{Y}^{\prime} \mathrm{Y} & 5 & 0.66 & \mathrm{YO}, \mathrm{Y}^{\prime} \mathrm{O}^{\prime} & 4 & 0 \cdot 27 \\ \mathrm{OO}^{\prime}, \mathrm{O}^{\prime} \mathrm{O} & 7 & 0 \cdot 58 & \mathrm{YO}^{\prime}, \mathrm{Y}^{\prime} \mathrm{O} & 5 & 0 \cdot 22 \\ \text { Total } & 29 & 0.55 & \text { Total } & 21 & 0 \cdot 28\end{array}$

(b) The nature of the mortality

$\begin{array}{lcccccc} & \text { H } & \text { R } & \text { PD } & \text { BD } & \text { UD } & \text { No. of eggs } \\ \text { Non-hybrid } & 0.53 & 0.15 & 0.08 & 0.07 & 0.17 & 651 \\ \text { Hybrid } & 0.34 & 0.20 & 0.09 & 0.06 & 0.31 & 496\end{array}$

(c) Hatch rates from crosses from within the

\begin{tabular}{|c|c|c|}
\hline Cross & No. of crosses & Hatch rate \\
\hline YY & 7 & $0 \cdot 29$ \\
\hline 00 & - & 一 \\
\hline OY & 3 & $0 \cdot 02$ \\
\hline YO & 3 & 0.39 \\
\hline $\mathrm{OH}$ & 6 & $0 \cdot 28$ \\
\hline $\mathrm{YH}$ & 7 & 0.16 \\
\hline Total & 26 & 0.23 \\
\hline
\end{tabular}

(d) The nature of the mortality

$\begin{array}{lcccccc} & \text { H } & \text { R } & \text { PD } & \text { BD } & \text { UD } & \text { No. of eggs } \\ \text { YY, OO } & 0.25 & 0.30 & 0.03 & 0.25 & 0.17 & 233 \\ \text { OY, YO } & 0.12 & 0.16 & 0.07 & 0.37 & 0.28 & 111 \\ \text { OH, YH } & 0.25 & 0.18 & 0.01 & 0.47 & 0.13 & 244\end{array}$

small, and the hatch rates were not normally distributed, confidence intervals were obtained using the $t$-test; this is fairly robust to deviations from normality. At a 95 per cent confidence level, the non-hybrid rate is between 0.45 and 0.64 , whilst the hybrid rate is between $0 \cdot 17$ and 0.40 . Combining these limits, we find that the fitness ratio is between 0.31 and 0.79 ; the selection operating at this stage alone is between 20 per cent and 70 per cent.

There were no consistent differences in survival, rate of development, fertility, or rate of egg laying between the various classes after hatching; the numbers involved are small, however. The results of the karyotypic analysis of the offspring are presented in table 3(a). (Only the totals for each class of cross are given; details of the states of the eggs from each of the 28 crosses, including the karyotypes of the various mutants, are contained in Barton, 1979 a.) Since there is a good deal of variation between pods and between crosses, $\chi^{2}$ tests cannot be used to test for differences in the frequencies of abnormalities between classes. The fraction of apparently normal embryos 
(S) varies greatly between crosses, but there is no consistent pattern to this variation. One would have expected a lower fraction to have survived from $F_{1}$ and perhaps backcross classes, since the hatch rates were found to be lower in the previous generation. However, the number of crosses here is smaller, and so these results do not contradict the findings described above. In any case, much of the failure of hybrid eggs was caused by death at hatching, which would not affect these pre-diapause figures unless it were caused by some chromosomal abnormality.

Embryonic failure mostly occurred at early stages (UD). About 3 per cent of the embryos were haploid; this could have been because of a failure of fertilisation. Some crosses were more liable to produce haploid eggs than others. About 0.5 per cent (or 1 per cent of the survivors) were polyploid; it is often difficult to work out just what the original genotype was, because of somatic variation. About 1.5 per cent (or 3 per cent of the survivors) were aneuploid in some way. One would expect non-disjunction of the sex chromosome trivalent in heterozygous females to account for some of this aneuploidy; some 22 and 25 chromosome embryos would result, although half of the aneuploid progeny would go undetected, since the $\mathrm{X}$ chromosome is indistinguishable from the large autosomes at mitosis. Out of the 538 eggs produced by heterozygous females, 5 had an acrocentric missing or extra, whilst out of 533 eggs produced by homozygous females, another 5 had similarly aneuploid karyotypes. Non-disjunction is clearly rare, and is unimportant in comparison with other causes of aberration.

The behaviour of the large B chromosome is interesting; there seemed to be considerable meiotic drag acting against it, both in males and females. The average transmission rate was 40 per cent, but it was much less in some crosses. In comparison, the B chromosome of Myrmeleotettix maculatus shows meiotic drag in the male, but meiotic drive in the female (Hewitt, 1973).

Podisma pedestris usually has two very small pairs of acrocentric chromosomes, but 5 out of the 56 parents in these crosses were heterozygous for a small metacentric chromosome. There was no significant drive or drag in these crosses, but sometimes two copies of the metacentric were passed on.

Although the variation between crosses made the detection of differences in the frequency of abnormalities difficult, it is probably reasonable to test for deviations from the expected equal ratios of normal karyotypes using the $\chi^{2}$ statistic, on the assumption that segregation ratios do not vary between crosses. Such tests are quite sensitive, since many eggs were scored. There are no significant deviations from equal transmission of the two sex chromosome types, but there is an excess of females in the OO class, and, less strikingly, of males in the $\mathrm{OH}$ class. These differences in sex ratio could be due to meiotic drive, or to differential viability. The $\mathrm{OH}$ class only contains a single successful cross, but the OO class contains six. The bias is only significant in one cross $\left(\chi_{1}^{2}=6 \cdot 1\right)$, but on the other hand, there is no significant difference in ratio between the crosses $\left(\chi_{5}^{2}=4 \cdot 8\right)$, and the overall ratio is significantly different from equality $\left(\chi_{1}^{2}=8 \cdot 0\right)$. The phenomenon is odd; it would be interesting to re-examine population $\mathrm{O}$. However, the fission/fusion polymorphism seems to segregate normally; table 3(a)(iii) shows that there is little difference in the frequency of the various chromosome types between mating and diapause. 
ป.

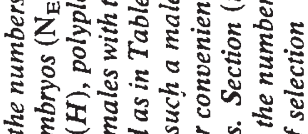

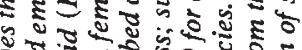
कू.

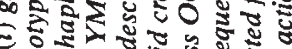

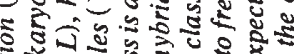
पुँ फ $\lesssim 50$

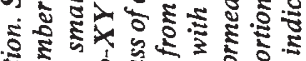
औ

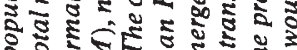
क. हैं

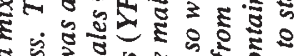

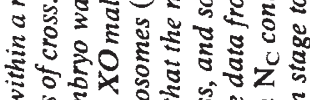

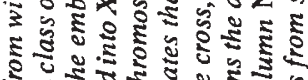

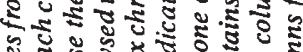

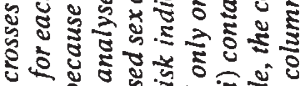
$m$ m ₹

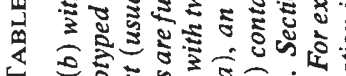
ङ .

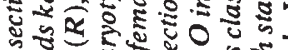
ปั นิ

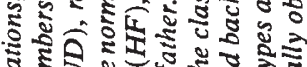

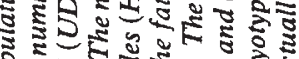
इำ हैँ

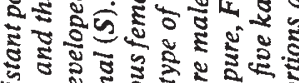

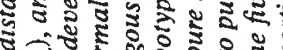

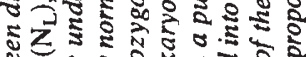

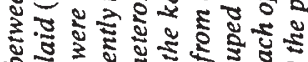

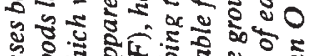

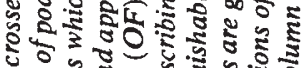

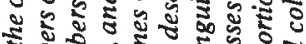

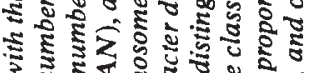
इ इ ปั

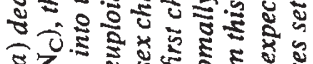

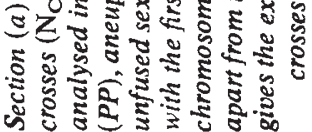

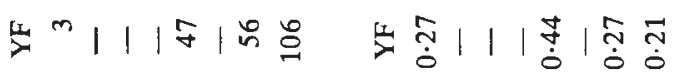

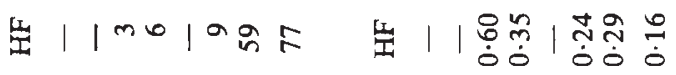

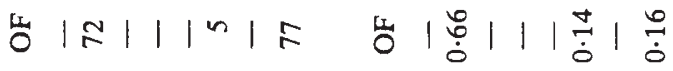

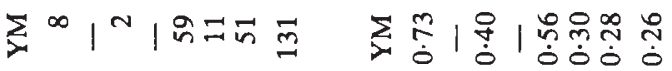


n

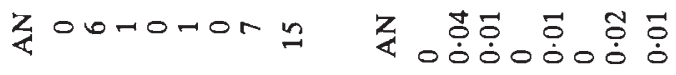

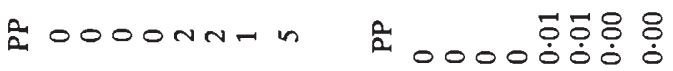

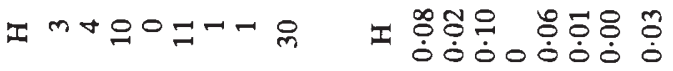

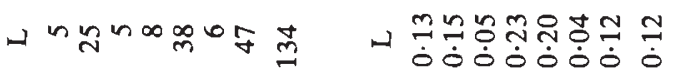
« ด

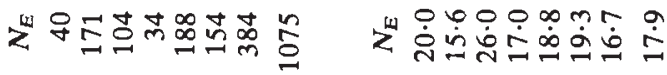
Z Znलํำ

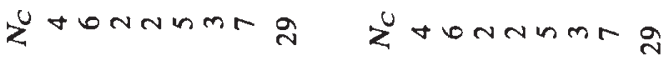

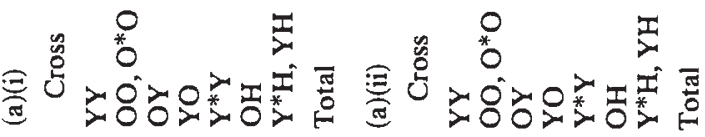




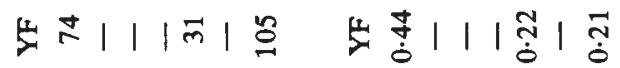

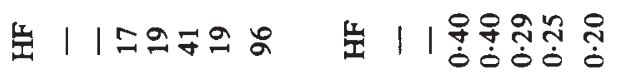
岁 |

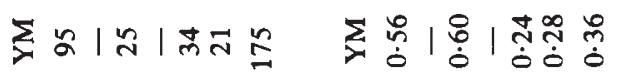

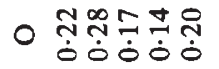
䒘

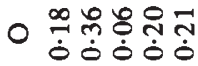

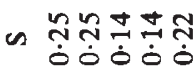

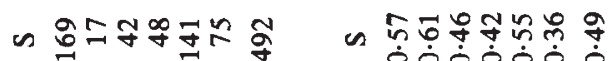

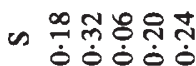

Z

Z

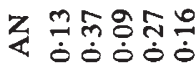

ํㅗำำำำำำ

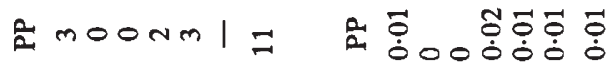

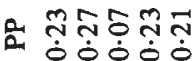

I

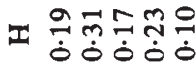

ᄀ

น กํำำ

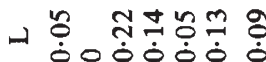

- ํํํํํำำำ

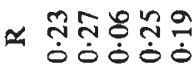

$\approx m+a \exists \pi_{\infty} \backsim$

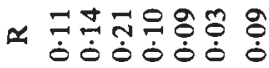

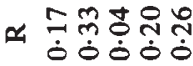

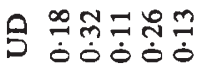

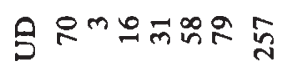

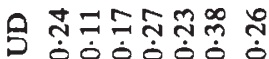

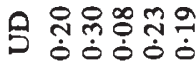

एแ

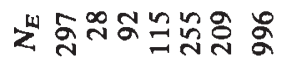



रूติ

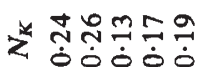

zัก

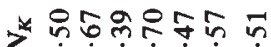

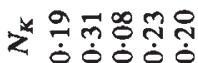

之ำกำำำ

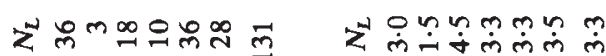

रำ

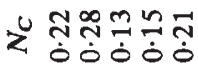

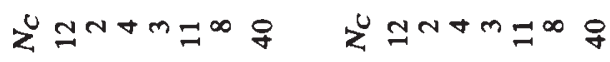

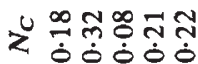

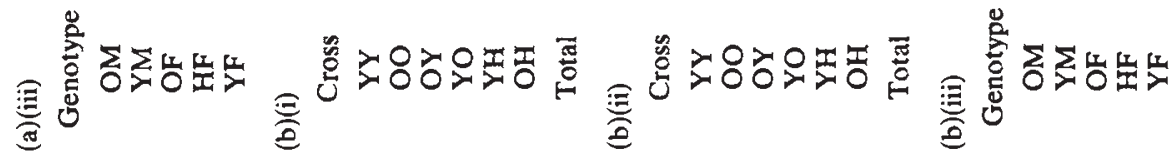




\section{(ii) Crosses between grasshoppers from within the cline}

As in the last experiment, there were no significant differences between the chromosomal classes in the date of laying, or in the numbers of eggs per pod. Hatch rates were much lower than before (an overall mean of 0.23 as against 0.45 ), apparently because many embryos ceased developing at or just before diapause (table $2(b, d)$ ). This reduction in hatch rate bears no relation to chromosome type. Hatch rates vary greatly between crosses, but there are no consistent patterns. The difference in overall hatch rate could be a real biological phenomenon, caused either by a peculiarity of this particular population, or by hybrid breakdown at the centre of the cline. However, it is also possible that these eggs were inadvertently treated differently in some way from the last batch.

The results of the karyotypic studies are presented in table $3 \mathrm{~b}$. This sample of parents provides the only information on female karyotype frequency, apart from a few small samples in Hewitt (1975) and John and Hewitt (1970). 20 XO males, 32 XY males, 5 XO type females, 19 heterozygous females, and $16 \mathrm{XY}$ type females were collected. These numbers are in Hardy-Weinberg proportions $\left(\chi_{1}^{2}=1 \cdot 2\right)$, and so there can be no strong assortative mating between the chromosome types. The chromosome frequency is the same in the two sexes $\left(\chi_{1}^{2}=0 \cdot 6\right)$.

Our expectations for this set of crosses are rather complicated. Apart from producing some infertility in heterozygous females through nondisjunction, a Robertsonian fusion might act directly on fitness through position effects, or by its reorganisation of the recombination pattern (see Hewitt and John, 1972; and Charlesworth and Charlesworth, 1975). Polymorphisms in each race would adapt themselves to the prevailing pattern of recombination, so that the rarer karyotype in the cline would tend to be selected against (see Bengtsson and Bodmer, 1976 for theoretical examples of the effect of an epistatic polymorphism on the evolution of a chromosomal rearrangement). The same selective force would be produced if other loci involved in the cline were linked to the fusion (Barton, 1979b). However, neither heterozygote sterility, or selection against the rarer XO karyotype, is suggested by these results; the fraction of apparently normal embryos varies somewhat between classes but no consistent pattern emerges.

Embryonic failure occurs mainly in the early stages, as before. About 3 per cent of the embryos are haploid. These embryos appeared perfectly normal, as did all the chromosomal aberrants. Presumably the maternal cytoplasm dominates at this stage. About 1 per cent of the embryos were polyploid, rather more than in the last set of crosses, and a further 3 per cent were aneuploid in some way, also more than in the last set. Again there is no evidence for non-disjunction. Out of 464 eggs produced by heterozygous females, 6 might have been produced by non-disjunction, whilst out of 532 eggs from homozygous females, 4 were similarly aberrant. Pooling this information with that from the last experiment, one obtains an upper limit of 1.6 per cent (with 95 per cent confidence) for the non-disjunction rate, expressed as a fraction of the surviving embryos.

The $\mathrm{B}$ chromosome is rare in the population from which this sample was taken, and so the meiotic drag found in the last set of crosses is not apparent. The segregations here do not contradict the previous transmission rate of 40 per cent, however. The small metacentric does not seem to be present, 
although it may have been missed; the crosses between pure populations were karyotyped after these, and the polymorphism was only noticed then.

There are no significant deviations from Mendelian segregation, either for the $\mathrm{X}$ chromosome or for the fusion. Overall, there is little deviation from the expected genotypic frequencies between mating and diapause (table 3(b)(iii)). There is no evidence for any selection on the karyotype.

\section{(iii) The transplant experiment}

The results of this experiment are shown in table 4. The initial numbers were calculated from the proportion of marked grasshoppers recaptured, on the assumption that the male and female populations were equal. The Valmasque site is quite well defined, being surrounded on three sides by trees, and the frequencies given are the averages over this area. At Lac Long, however, the site is not so restricted, and the transplanted gene spread out beyond the area over which the painted grasshoppers had been scattered. The initial (1976) frequency given in table 4 is the average over this larger area; the frequencies for later years are averages over the same areas.

\section{TABLE 4}

The results of the transplant experiment. The first section contains the numbers involved in the Lincoln index estimate of population size, and the numbers transplanted. The second contains the results of subsequent sampling of males, and the third the 95 per cent confidence limits on karyotype frequencies. Since the fusion is sex linked, one would expect the frequency in males to equal that in females in the previous generation, and that in females to be the average of the male and female frequencies in the previous generation

\begin{tabular}{|c|c|c|c|c|c|}
\hline & \multicolumn{2}{|c|}{ Lac Long } & \multicolumn{2}{|c|}{ Valmasque } \\
\hline & & male & female & male & female \\
\hline $\begin{array}{l}\text { Released (marked) } \\
\text { Recaptured (marked) } \\
\quad \text { (unmarked) } \\
\text { Released (foreign type) }\end{array}$ & & $\begin{array}{r}11 \\
4 \\
31 \\
28\end{array}$ & $\begin{array}{r}14 \\
7 \\
56 \\
19\end{array}$ & $\begin{array}{r}10 \\
3 \\
48 \\
20\end{array}$ & $\begin{array}{r}10 \\
5 \\
29 \\
40\end{array}$ \\
\hline $\begin{array}{l}1977 \text { sample } \\
\text { native males } \\
\text { foreign males } \\
1978 \text { sample }\end{array}$ & & $\begin{array}{r}76 \\
0\end{array}$ & - & $\begin{array}{r}80 \\
0\end{array}$ & - \\
\hline $\begin{array}{l}\text { native males } \\
\text { foreign males }\end{array}$ & & $\begin{array}{r}127 \\
7\end{array}$ & - & $\begin{array}{r}89 \\
0\end{array}$ & - \\
\hline $\begin{array}{l}95 \text { per cent limits on } \\
\text { frequency of } \\
\text { transplanted } \\
\text { karyotype }\end{array}$ & $\begin{array}{l}1976 \\
1977 \\
1978\end{array}$ & $\begin{array}{r}0.08-0.20 \\
0-0 \cdot 05 \\
0.02-0.11\end{array}$ & $\begin{array}{c}0.07-0 \cdot 26 \\
- \\
-\end{array}$ & $\begin{array}{r}0.06-0.20 \\
0-0.05 \\
0-0.04\end{array}$ & $\begin{array}{c}0 \cdot 10-0 \cdot 29 \\
- \\
-\end{array}$ \\
\hline
\end{tabular}

Substantially fewer transplanted grasshoppers were found than expected; none were found at either site in 1977 , whilst only seven were found at Lac Long in 1978. This could be because the foreign type did poorly in the first year, because it dispersed outside the area searched, because hybrids were selected against, or because the native population was higher than that indicated by the mark-release-recapture estimate. Marked grasshoppers were seen mating with the native population in the first year; it is unlikely that the transplanted individuals arrived late in the laying season, since 
native adults had only emerged a few days before the transplant. This effect is therefore unlikely to explain much of the drop in frequency. Damage in transit is also rather unlikely; Podisma nymphs have survived the much more traumatic journey back to England very well. It is possible that some transplanted genes spread outside the area searched; however, it is unlikely that dispersal is fast enough to explain much of the loss (Barton and Hewitt, $1980 \mathrm{~b}$ ). It is also possible that the initial native population was augmented, after being measured, by the moulting of nymphs through to adult. Few nymphs were seen at either site on the day of the transplant, though there were more at the shadier Valmasque site. These arguments leave selection against hybrids as the most plausible explanation; crosses between populations $\mathrm{O}$ and $\mathrm{Y}$ (very close to these sites) showed greatly reduced $F_{1}$ hatch rates in the laboratory.

\section{Discussion}

These crosses have shown that there is considerable incompatibility between populations spanning the cline, though not between separated populations on the same side. This incompatibility acts surprisingly early, at and before the hatching of the first generation (the $F_{2}$ viability was not investigated beyond diapause). There is no evidence for any chromosomal involvement; a Robertsonian fusion would only be expected to produce infertility in the $F_{1}$, and perhaps some hybrid breakdown in the $F_{2}$ because of altered recombination patterns. Neither of these was observed; in particular, the non-disjunction rate was very low $(<1.6$ per cent, and perhaps zero), in comparison with other forms of aberration. It should be noted that measurements of the non-disjunction rate based on observations of the orientation of the chromosomes at metaphase may be misleadingly high, since the chromosomes may eventually orient themselves correctly (Nicklas, 1967).

These findings are consistent with those from other hybrid zones (see Barton and Hewitt, 1980c). Often, many characters are involved in such zones, and the contribution of the chromosomal differences may not be of major importance. For example, races 17 and 19 of Vandiemenella viatica are incompatible not only because of meiotic irregularities, but also because of partial failure of sperm transfer, which results in a high frequency of parthenogenetic embryos in hybrid crosses (White et al. 1969; and Mrongovius, 1979). Similarly, the narrow clines between the various chromosomal races of Spalax ehrenbergi involve not only chromosomal differentiation, but also marked behavioural differences; very few abnormal karyotypes are found in mixed populations (Nevo and Bar-El, 1976). In the case of Podisma, both the width of the chromosomal cline (Barton and Hewitt, 1980a) and the results of these crosses, suggest that the karyotypic difference between the two races is only a marker for other, more fundamental, differences.

Acknowledgements.-I would like to thank Dr G. M. Hewitt, and M. W. Shaw, for their help in collecting these samples, Mrs T. M. East for her help in rearing them, and M et Mme Aviotti for their hospitality in France. This work was supported by a N.E.R.C. studentship, and by an S.R.C. grant to Dr G. M. Hewitt. 


\section{REFERENCES}

BARTON, N. H. 1979a. A narrow hybrid zone in the alpine grasshopper Podisma pedestris. Ph.D. thesis, Univ. of East Anglia, Norwich.

BARTON, N. H. 1979b. Gene flow past a cline. Heredity, 43, 333-339.

BARTON, N. H., AND HeWITT, G. M. $1980 a$. A chromosomal cline in the grasshopper Podisma pedestris. In prep.

BARTON, N. H., AND HEWITT, G. M. $1980 \mathrm{~b}$. A measurement of the dispersal rate in the grasshopper Podisma pedestris. Ms. submitted to Evolution.

BARTON, N. H., AND HEWITT, G. M. 1980c. Hybrid zones and speciation. In Essays on evolution and speciation in honour of M. J. D. White, ed. W. Atchley and D. S. Woodruff. Cambridge Univ. Press.

BENGTSSON, B. O., AND BODMER, W. F. 1976. On the increase of chromosome mutation under random mating. Theor. Popln. Biol., 9, 260-281.

CHARLESWORTH, B., AND CHARLESWORTH, D. 1975. An experiment on recombination load in Drosophila melanogaster. Genet. Res. Camb., 25, 267-274.

HEWITT, G. M. 1973. Evolution and maintenance of B chromosomes. Chromosomes Today, 4, 351-369.

HEWITT, G. M. 1975. A sex-chromosome hybrid zone in the grasshopper Podisma pedestris (Orthoptera:Acrididae). Heredity, 35, 375-387.

HEWITT, G. M., AND BARTON, N. H. 1979. The structure and maintenance of hybrid zones as exemplified by Podisma pedestris. In Royal Entomological Society 10th Symposium: Insect cytogenetics, Blackwells.

HEWITT, G. M., AND EAST, T. M. 1978. Effects of B chromosomes on development in grasshopper embryos. Heredity, 41, 347-356.

HEWITT, G. M., AND JOHN, B. 1972. Interpopulation sex chromosome polymorphism in the grasshopper Podisma pedestris. II Population parameters. Chromosoma, 37, 23-42.

JOHN, B., AND HEWITT, G. M. 1970. Interpopulation sex chromosome polymorphism in the grasshopper Podisma pedestris. I Fundamental facts. Chromosoma, 31, 291-308.

KELLY-STEBBINGS, A., AND HEWITT, G. M. 1972. The laboratory breeding of British grasshoppers. Acrida, 1, 233-275.

MRONGOVIUS, M. J. 1979. Cytogenetics of the hybrids of three members of the grasshopper genus Vandiemenella (Orthoptera:Eumastacidae:Morabinae). Chromosoma, 71, 81-107.

NEVO, E., AND BAR-EL, H. 1976. Hybridization and speciation in fossorial mole rats. Evolution, 30, 831-840.

NICKLAS, R. B. 1967. Chromosome micromanipulation. II Induced reorientation and the experimental control of segregation at meiosis. Chromosoma, 21, 17-50.

WHITE, M. J. D. 1973. Animal cytology and evolution, 3rd ed. Cambridge University Press.

WHITE, M. J. D., KEY, K. H. L., ANDRÉ, M. J., AND CHENEY, J. 1969. Cytogenetics of the viatica group of morabine grasshoppers. II Kangaroo Island populations. Austral. J. Zool., 17, 313-328. 